\title{
Ineducable us: the applications and contexts of microscopy used for the characterisation of historic building materials
}

\author{
John J. Hughes ${ }^{\text {* }}$ \\ ${ }^{\mathrm{a}}$ School of Engineering and Computing, University of the West of Scotland, Paisley, PA1 2BE, Scotland
}

Received: 19 December 2017 / Accepted: 28 December 2017 / Published online: 31 December 2017

C The Author(s) 2017. This article is published with open access and licensed under a Creative Commons Attribution 4.0 International License.

\begin{abstract}
The analysis by microscopy of the compositions and microstructures of geomaterials found in historic structures and buildings is integral to archaeological, art-historical, conservation and restoration-related investigations, and supports decision making for material replacement and repair. In archaeology there is a need to elucidate past social, economic and technological processes, and to understand the environmental impacts of past human activities related to materials use. Standard light and electron microscopy are most commonly employed, but high resolution methods such as transmission electron and three-dimensional tomography such as $\mu$-CT are also being used. Experimental and novel developments, where they overlap with advanced materials science, are uncommon. The application of scientific characterisation frames cultural heritage value, reinforcing our understanding of authenticity and integrity. Characterisation is constrained, in turn, by the values system that operates in cultural heritage. International charters and conservation philosophy necessitate the application of science to contextualising conservation. However, the appearance of science in heritage work has also led to the performance of science for its own sake ('endoscience', sensu Muñoz Viñas, Contemporary Theory of Conservation, Routledge, 2011). This moves some to suggest that there is a disconnect between scientific work and its practical value. Apparent communication problems between scientists applying microscopy and other stakeholders require changes to management of material characterisation in heritage projects.
\end{abstract}

Keywords: Microscopy; Cultural heritage; Conservation

\section{Introduction}

Scientific methods of material analysis are accepted, and indeed often considered an essential, integral part of the conservation of heritage objects, buildings and sites. However, scientific activity forms only part of the wide interdisciplinary field of heritage conservation. In this paper, microscopy, as applied to the characterisation of materials in historic structures will be used to consider the interaction of science with conservation.

Historic, traditionally constructed buildings are common in our towns and cities, and are often protected by legislation against alteration and demolition. This is because they are valued by us for the evidence of the past that they contain. They are a repository of embodied energy, and remain as functional, useful resources. We therefore pay attention to the conservation of structures, through maintenance and repair, to slow and manage decay of their materials and their functional durability, in addition to their value as documents of the past and as sources of knowledge about previous societies and cultures. The understanding of materials, their compositions, textures and behaviours are therefore very important in efforts to conserve these values.

For historic buildings, damage to materials, especially stone, caused by weathering, poor maintenance and pollution, has been recognised for some time as a problem [2, 3]. During the late 19th and 20th Centuries it was considered to be an issue that can, and should be addressed through scientific investigations, experiments and engineered materials solutions. It can be contended that the public understanding of conservation conflates scientific investigation as conservation per se. This is contentious, as both scientists and those responsible for conservation can distinguish themselves from each other quite strongly. Muñoz Viñas [1] places scientists as part-players in a rich constellation of stakeholders that surround conservation efforts (Figure 1), notably not as the primary agents of conservation activity, alongside other technical specialists. Only conservators 
interact directly with the object of conservation in his interpretation. In this paper, microscopy will be considered as an area of scientific activity applied to conservation in the historic built environment. What do scientific, and engineering investigations that assist conservation of heritage actually do? What value, and values, do they add to the conservation effort? Below, the application of microscopy in 'heritage science' will be briefly reviewed, followed by a discussion of the additional constrains that heritage conservation practice places on scientific activity. The intention is that this can be read as a proxy for technical interventions in heritage, not just those using microscopy.

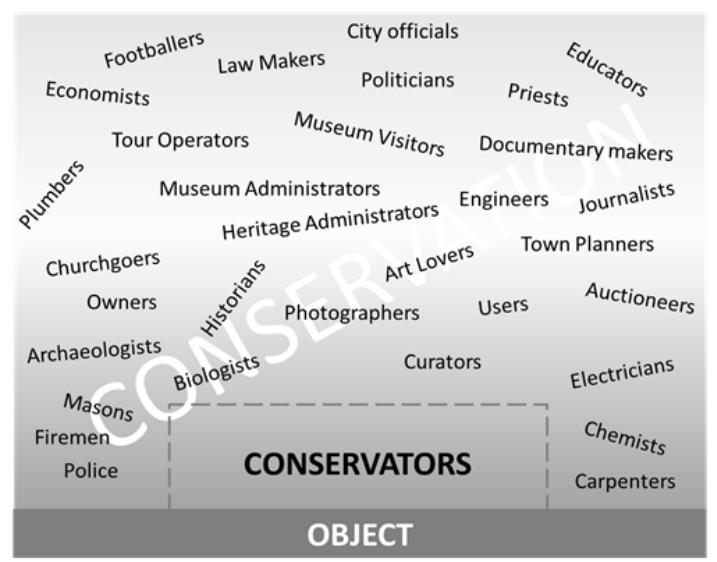

Figure 1. The relative positions of various actors in conservation, in relation to the object of conservation (or the building and site, in the current author's interpretation), redrawn and amended, slightly, from [1] (with permission of the author). Sub-types of scientist can be seen in the population (including arguably Archaeologists). Geologists and petrographers are conspicuous by their absence, indeed scientists in general, however [1] did not intend this as a proscriptive or complete list.

\section{Application of microscopy to the built historic environment}

The use of imaging, generally, in the cultural heritage field is wide, applied to any material that can be found in a structure or object. The use of microscopy (sensu stricto) is well known in the popular understanding of what might be considered 'high' cultural heritage- fine art conservation in particular $(4,5]$, typified by the analysis of paint layers cross sections [6] and $x$-ray and infra-red analyses of canvases [7]. Petrographic analysis of cultural materials itself has an application history in archaeological work stretching back at least to near the advent of the use of thin sections for lithological characterisation. The pioneer of thin section studies of geomaterials, H.C. Sorby, is himself reported to have analysed the provenance of stone samples from an archaeological site in Oxfordshire, in 1869 [8].

Increasingly, resources are applied to forms of macroimaging, including the use of laser scanning [9], thermal imaging [10, 11], microwave moisture mapping [12], and combinations of these, and combinations with other NDT and petrography [9]. Sometimes utilising remote controlled airborne platforms (e.g. UAVs) for the monitoring and characterisation of whole, difficult to access structures [13]. For many of these methods, though strictly not imaging per se., they typify an approach where a property is mapped and then presented in a visual format after processing of the results.

It is not so commonly understood, except in the expert community, that microscopy is a powerful methodology for the study of all cultural materials, including those in the built environment. Excellent reviews of techniques and methodological protocols for the application of microscopy in this area can be found by Reedy [14] and Elsen [15]. This paper focuses on geomaterials used for construction (sensu Ingham, [16]); stone, brick, concrete, ceramics and mortar, and does not reiterate its predecessors, but considers the place of analysis in active conservation. The following offers a brief outline, and the author's synthesis, of the ways in which microscopy is used to increase knowledge of materials and to support conservation.

\section{Establishing a baseline condition assessment and processes of decay using microscopy}

A fundamental question in construction materials' repair and conservation, not just for historic buildings, is simply; "what is this?" On many occasions the first-order answer to this is simple and obvious to most, even non-experts, at the level of basic material categories such as stone, brick, and concrete. At a slightly deeper, qualitative level, an expert can distinguish, by eye and with experience, the type of stone, the likely strength and properties of brick and concrete, and even suggest their provenance. Beyond this, there are questions that require more detailed, sometimes quantitative analysis. For example, the need for a formal classification of stone, the understanding of the exact composition of a damaging salt, the precise properties of a brick, the air content, clinker composition or W/B ratio of concrete or cement-bearing mortar. These are questions of significance for historic and modern structures.

An audit of what exists, that comprise a historic structure is a prerequisite for effective conservation and to allow for understanding change into the future. Materials characterisation offers a baseline for comparison with future understanding of condition, the nature of change and its causes. Characterisation defines condition and also allows the diagnosis of agents of change, the factors that cause deterioration, and can clarify necessary courses of conservation intervention. It also, in this context, defines the historic fabric and reinforces the authenticity and integrity of the heritage 'asset', by the sheer force of the knowledge about the material reality of the object or building [1].

Advanced characterisation involves instrumental analyses, and microscopy plays a key part in this. It does, however, require specialist facilities for specimen preparation (impregnation, cutting, lapping and polishing), specialist equipment (expensive microscopes) and specialist knowledge for interpretation. Often practitioners are academically trained in petrographic techniques as geologists / mineralogists, or in other microscopy methods 
as materials scientists. In the following, some recent Scottish, and other, examples will demonstrate the scope of such characterisation, and its relationship to core conservation practice, or not.

Hyslop et al. $[17,18]$, working in the City of Glasgow, using polarised transmitted light microscopy, characterised sandstone from over one hundred historic buildings. Standardised petrographic classification was applied [19], and the results used to distinguish ten sandstone varieties. This was combined with visual assessment of façades, to characterise condition, forms of decay and the quantity of decay, in turn related to how much stone was needed for repair.



Figure 2. Examples of microscopy applied to the fundamental characterisation of building sandstone from the interior of the Kelvingrove Museum, Glasgow. a) Remaining panel of uncleaned stone, with cleaning test panels. b) PPL PLM image of a thin section of stone, porosity is filled with blue-dyed epoxy resin. Textures and mineralogy can be readily described, and the stone classified. c) SEM-BSE image showing a cross section of the soiled outer surface of the stone, allowing for elemental analysis and precise mineral identification of the components of the stone.

Petrographic analyses were used to specify the type of stone needed for repairs, and to allow comparison with available sandstone resources still quarried, to suggest a matching lithology for repair. This work was the first large scale study of stone from a Scottish city that also classified and described the material on the microscale. The results provide a baseline condition statement and resource for future conservation, and context for the identification of unknown stone from the city.

Also in Glasgow, the author [20], analysed sandstone from the interior of the Kelvingrove Gallery, characterising and classifying the petrographic variability related to colour variation, and providing some understanding of the nature of the soiling of the stone (Fig 2). Scanning Electron Microscopy (SEM) was applied to polished thin sections and cross-sections, and chemical analysis of components (framework grains, cement and alteration products) of the stone by Energy Dispersive Spectroscopy (EDS). There are numerous additional examples of this form of characterisation of stone, available in the literature (e.g. [21]).

Understanding stone decay and conservation is, arguably, the significant subject of research and applied investigation of cultural heritage materials. It attracts a great deal of attention from the conservation community, practical conservators, architects, engineers and materials scientists (mineralogists, chemists, geologists), and generates many contributions to peer reviewed literature and conference proceedings. Microscopy plays an important role in this work; the analysis of a recent conference dedicated to stone conservation ([21] op cit.), reveals that out of 150 contributions, 38\% presented results from microscopy, mostly optical and electron microscopy and 10\% utilised more advanced methods such as TEM and $\mathrm{u}-\mathrm{CT}$. Analysis by a combination of methods is common.

Damage diagnosis is perhaps the most important reason for the use of microscopy to characterise materials in historic structures. Microscopy is valuable for the identification of features associated with mechanical decay, such as cracking and deformation of components, at scales invisible to the naked-eye. It enables the characterisation of the products of chemical and mineralogical alteration caused by processes of weathering, from natural, and also anthropogenic stressors such as sulphate, nitrate and particulate pollutants. Petrographic analysis (optically and by SEM / EDS) can be utilised to identify phases in the original and the altered materials, and to visualise the spatial interrelationships and textures of phases. Adopting stratigraphic principles from 'macro' earth sciences and archaeology, micro-fabric analysis sheds light on the patterns and chronology of damaging change, and therefore its mechanisms [22-24]. This information can be utilised to seek appropriate remedies and management strategies. Often these mechanisms are dynamic processes, which under experimental simulation can also be studied using microscopy [25]. 


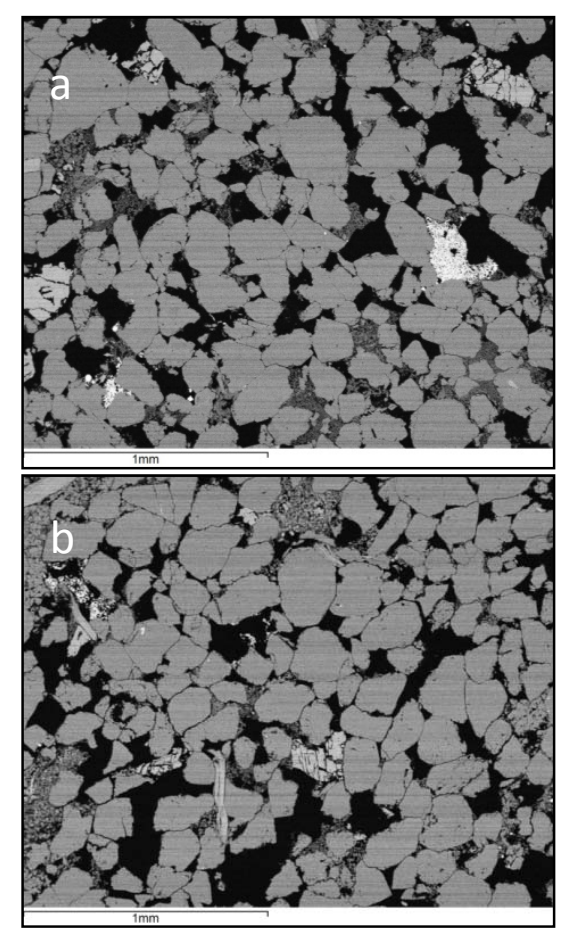

Figure 3. SEM- Backscattered Electron images of sandstone: a) a control sample and b), a sample that was exposed to $900^{\circ} \mathrm{C}$ for 4 hours. This was used to assess the effects of fire damage on stone as part of a comprehensive analysis of the mechanical and compositional effects. There is a suggestion in these images of a separation of grains in the sample exposed to elevated temperature, that may correlate with observation of changes in other physical and mechanical measurements (author's own work).

Microscopy is also utilised to analyse experiments on the effects of conservation treatments in controlled laboratory settings, for example the characterisation of the level of damage in deliberately weathered control specimens of stone, intended to be used in further experiments where interventions for the amelioration of damage are developed [26]. Looking at the effects of consolidants, for example microscopy is used for determining penetration depth and textural relationships of treatments within the microstructure of materials [27]. A related activity is the experimental simulation of damage caused by acute events, for example stressors such as fire and armaments/projectile impacts $[28,29]$, in which microscopy can play a role in evaluating effects (Fig 3).

\section{Mortars, including early and recent hydraulic materials}

Microscopy has also been extensively applied to the characterisation of mortars from historic buildings ([15] for an earlier review), and is included in most standardised analysis protocols [30]. This is done for several reasons, however, most often not related to condition or damage diagnosis. Instead, analysis is used to support repair and replacement strategies in building conservation, as mortar is usually considered expendable. There is a requirement to understand and specify like-for like replacements for conservation, repair and authentic restoration. Microscopy is often used in combination with other analysis techniques, in corroboration of mineralogical identifications, such as X-Ray Diffraction.

Transmitted light microscopy, when applied to standard thin sections of mortar, allows for the identification of the types of aggregate, additives such as forms of natural and artificial pozzolana, the type of binder, and also textural information such as the size and shape of the aggregate and other particles (e.g. lime inclusions, or "binder related particles", $[15,31,32])$ and the ratio of binder to aggregate. Optical and electron microscopy can also furnish quantitative information, using manual point counting and also automated image analysis to determine binder : aggregate ratios and particle size distributions [33].

Microscopy is a vital technique for the analysis of mortars as they present as complex and changing materials [15], and the richness of the material information that they include is best determined by skilled microscopy [34]. Mortars are complex man-made materials, that can defy straightforward classification due to the variability of their components, originating from local and highly contingent material sources and non-standardised construction and manufacturing practices. The ability of microscopy to facilitate the description of characteristics in a material, that relate to human agency and practical material choices, mean that it is very valuable in support of archaeological investigations, of mortars [34, 35] and but also of other ceramic materials, such as pottery and bricks [36].

The analysis by microscopy of hydraulic components in historic mortars has developed significantly in recent years. The author, in a study of mortars from the city of Aberdeen in Scotland [37], through the application of optical microscopy combined with SEM-EDS, characterised mortars used for the construction of granite masonry buildings during the late 19th and early 20th centuries. It was revealed that the mortars were compositionally tailored to function; non-hydraulic lime based mortars for bedding, and early Portland cements used for pointing historically, something that is not normally recommended today. The identification of hydraulic components $\left(\mathrm{C}_{3} S, \mathrm{C}_{2} \mathrm{~S}\right)$ in the pointing mortars using qualitative microscopy was corroborated with additional methods, including XRD and Mercury Intrusion Porosimetry. This is a small example of the common use of multiple methods of analysis, as part of a larger scheme [30].

The analysis of such historic hydraulic mortars is particularly amenable by microscopy, including the application of reflected light. The analysis of remnant clinker grains is routinely performed using chemical etching to reveal normally obscure mineralogical structure and also colour [38]. Combined with EDS, it is possible to determine types of clinker and to even understand the temperature of formation of the mineralogical assemblages. Other methodological approaches to analyses are also followed, for example Schmid and Dariz [39] applied Raman microscopy to the characterisation of hydraulic, Roman cement mortars, which allowed for the identification of various calcium silicate, aluminate and sulphur minerals at a sub-micron resolution. Deikamp et al. [40] analysed 16th C 
dolomitic mortars from Austria, and were able, using Fourier Transform Infra-Red microscopy, to map the distribution of hydraulic reaction products around aggregates and pozzolanic additives.

There are also many examples of characterisation by microscopy of unusual formulations of mortar, often from buildings constructed during the late 18th through to the early 20th Centuries, before standardisation and economies of scale homogenised material specification. These include mortars prepared with Alum shale in Sweden [41] and the use of unusual aggregates, such as iron fragments, in Austria [42]. Microscopy allows for clear and transferable visual characterisation of the materials, which through publication serve as a resource to other analysts faced with similar materials situations.

\section{Analysis in support of conservation interventions}

There is a perennial need to understand the materials comprised in historic buildings, to enable immediate decisions on conservation actions and interventions. In this context, microscopy has been applied extensively. For example, for the analysis of orthogonal cross sections of layered wall coverings, that support decorative elements or are sculptural, to understand material morphology and the order and methods of application [43]. Commonly, as mentioned above, microscopy allows for the detailed determination of the compositional characteristics of mortar materials, and in the example of stone characterisation by Hyslop et al. [17], allows the matching of replacement materials at a microstructural level. This can support the design of authentic repair strategies, from the choice of materials to the principles of application.

The work of Gulotta et al. [44] describes the effects of varying cleaning methods of marble sculptures investigated by optical and electron microscopy. The analysis contributes to the optimised choice of cleaning method and provides documentation of material effects also at the microscale. In another study the material nature of colour change due to laser methods of cleaning was investigated using very high resolution transmission electron microscopy [45]. These methods furnish scientific materials information, that may or may not be incorporated into conservation decision making. Nonetheless, there is an acceptance that increasing knowledge of the effects of actions, even when derived from technical analysis that is non-traditional, is valuable, if not now, then at some future point.

Science conducted in the support of conservation not only comprises of direct characterisation of historic assets, but is also performed as experimentation, in order to determine fundamental materials properties. This is conducted in highly constrained circumstances, and is often criticised by conservators and heritage professionals as being unrealistic and therefore rather pointless [46]. For example the understanding of salt dynamics is advanced by direct in-vivo observation of salt crystallisation [47], (though of course this work is clearly scientifically valuable). The effects of conservation treatments, such as cleaning and consolidation, are also amenable to investigation using microscopy $[27,44]$. This can be to characterise samples taken from in-situ treatments, and the results used to correlate to performance against requirements (for example penetration depth) and also longer term durability behaviours.

\section{Archaeological characterisation}

In an archaeological context, microscopy furnishes information that increases our knowledge of materials relating to past human activities. This involves specifying a baseline composition, essentially a statement of what exists, securely recorded, as knowledge of past material handling, construction techniques and the choices of historic builders [48]. There is also significant interest in the source of materials, so that social-economic reconstructions can be developed, for example sources of pozzolana used by Roman builders in concrete and mortars [49]. In this research, microscopy, both optical and SEM is applied to the understanding of the nature, the abundance and variety, and the behaviours of pozzolanic additives in ancient concretes and mortars. Jackson's petrographic efforts identify the materials used and suggest linkages to specific geological formations and quarries. The use of microscopy also allowed for the unravelling of complex dynamic mineralogical processes that take place in a low temperature salt water hydrothermal environment, and provides evidence for the roots of multi-millennial durability.

Provenance determination is also possible from the analysis of lime inclusions, where the partial remains of the original limestone used for the production of the binder phase in a mortar remains. The texture of the protolith can remain as a pseudomorph of the original texture [32] allowing matching with source. This is enhanced where unburnt cores within grains preserve original carbonate lithology, permitting elemental analysis on the microscale with EDS, and potentially other techniques, such as FTIR microscopy [40], and also thermal analysis to understand the composition of archaeological lime based materials [35].

There are many examples also of the use of microscopy, often allied to additional chemical and isotopic analyses, for the provenance identification of the lithologies comprising heritage objects, such as sculptures (particularly marble, e.g. [50]). In these, petrographic methods are used to describe textural and mineralogical characteristics, that can be matched against candidates for source. This is often correlated with geochemical analyses that allow for a deeper statistical scrutiny of similarities.

\section{Summary of applications and uses of microscopy}

Microscopy, therefore, is (non-exclusively) applied to the characterisation of historic building materials for reasons of condition assessment, baseline characterisation to measure change into the future, for the matching and authentic specification of repair materials, for the development of new conservation treatments (understanding their efficacy) and the understanding of the mechanisms of dynamic decay and repair processes. In archaeology it is applied for recording, to 
understand the materiality of structures and objects, the provenance of source materials, their processes of manufacture and processing and also for reasons of conservation. Microscopy is not used in isolation, mostly, but complements other forms of mineralogical and chemical analysis. It provides mostly qualitative and descriptive information but can furnish quantitative measures also, when combined with methods such as point counting and automated image analysis, and spatial compositional analysis. Methods include optical (transmitted and reflected light) and electron microscopy with EDS, and other methods such as TEM, $\mu$-CT, FTIR and Raman microscopy, all of which have been utilised in relation to the analysis of historic construction materials. Future innovation and improvements may come about through increased information and more sophisticated interpretations. However, the key issue is perhaps the non-technical one of the integration of scientific observations and methodological approaches with conservation actions. This is discussed in the next section.

\section{Conservation philosophy and the technical characterisation of historic building materials}

The preceding sections provide evidence for the use of microscopy in heritage applications, in building conservation and archaeological contexts, for the identification of material properties and behaviour. Any link to practical conservation is mostly implied, and for the large part taken for granted as being a common good. Greater knowledge of material assets, from scientific microscopy, works clearly to enforce the understood truth of the object concerned and how this is embodied in its materiality. However, much anecdotal experience, and some written opinion suggests that the link to practical conservation is often lacking when science is performed;

"Scientists just give you the data, you always have to put it in context." [51]

This quotation is from an architect during an interview given for a project looking at the links between conservation and science, and how they both intersect with concepts such as authenticity. It is quite a controversial comment to make within earshot of a practicing scientist. However, the sentiment it summarises will probably be familiar to scientists working with heritage, and even to conservators working in the field. It can be argued that scientists too often situate their work in isolation from practical application [46, 52]. This leads to conservators and other heritage professionals questioning the role of science; to quote Gerdwilker [53]: “..conservators...question the scientists' ability to relate their findings to the context of their projects." Nevertheless, despite these reservations, the use of science for the understanding and the protection of cultural heritage is accepted, and actively encouraged. How did this come about, and what are its consequences for the practice of science, in applying materials analysis methodologies such as microscopy?

The evolution of Western, mostly European conservation philosophy from the 19th Century onwards, puts the preservation of original material fabric as the primary aim [54], for reasons, that some argue, stretch back to the middle ages when material relics were imbued with religious significance. Despite influential critiques of values-based approaches to preservation [55] the material-curatorial approach won the day (though today there is a greater recognition of the intangible aspects of heritage [56]). This was perhaps due to the advocacy of workers such as John Ruskin and the codified values that the Society for the Protection of Ancient Buildings (SPAB) promulgated in Britain in the late 19th Century. This raised the conservation, rather than conjectural restoration of historic buildings to a high level of principle. There was, and to some extent still, a conflict between this Ruskian conservational approach and continental European trends towards aesthetic restoration to an earlier period, favoured by the likes of Violet Le Duc [54]. Nevertheless, both approaches privilege the material over the functional, or the intangible. The preservation of historic fabric and its understanding for the purposes of restoration, became central to conservation efforts. This became formalised during the 20th Century, when there were calls to ensure an internationally agreed basis for the need for, and the methods and conduct of, conservation actions. The adoption of internationally agreed conservation charters addressed this in a fundamental way $[57,58]$.

During this time the application of science to cultural heritage materials' conservation grew (exemplified by the work of Plenderleith, $[4,59])$, and was also influenced by an increasing realisation that heritage required protection, implicit, for example, in the work of specialist groups during the 2nd World War, who looked to repatriate misappropriated objects, but also to mitigate their poor treatment during times of conflict. Indeed today there is great concern over the fate of cultural heritage in the face of often ideologically driven deliberate destruction, not just the collateral damage inherent in active conflicts [60]. Efforts to ensure protection in such circumstances required action on material fabric, and notable, but not alone amongst specialists involved, are scientists. There was also a growing awareness of the vulnerability of heritage to acute events, for example, accentuated by the dramatic floods in Florence in 1966, the response to which is acknowledged as a catalyst for the improved application of scientific methodologies to heritage conservation. In relation to our purpose in this paper, the Venice charter, in article 2 states;

"The conservation and restoration of monuments must have recourse to all the sciences and techniques which can contribute to the study and safeguarding of the architectural heritage." [58]

This is on the first page of the commonly cited version of the document, and could not confirm a view of the importance of the sciences in heritage more. However, all is not so straightforward as it might appear, there are a number of complicating factors, and barriers to the action of science in conservation, otherwise scientists would be conservators, but they palpably are not. In addition, it is important to state that a greater recognition of the intangible values associated 
with heritage has evolved in recent decades (e.g. the Nara Document on Authenticity, [56]).

Tennent [46] states, in a discussion of practical conservation science that;

"the prime function of a conservation scientist..(is)..to provide knowledge or technical information which enables more effective conservation of cultural heritage,.."

This is a simple clarification of the generally accepted role of scientific investigations in cultural heritage (that often involve the application of microscopy), and one that is, as Tennant opines, difficult to disagree with. This approach also establishes a simple requirement for the consideration of the role of science in cultural heritage conservation (i.e. it must be effective). Thus Tennent adds a qualification, that scientific activity applied in conservation is only to be considered conservation science, "when conclusions can be drawn that are demonstrably relevant to improving conservation efforts". He also distinguishes the idea of fundamental studies, as mentioned above, that often concern issues of long term behaviour, and impacts of interventions, from applied, practical, sometime ad hoc solutions to immediate problems. The latter, by these considerations is more likely to be classified as conservation science, though the former is more visibly science, at least from a scientist's point of view. The latter, time, budget, and infrastructure limited is more what Torraca [61] called for as the evolution of the "conservation technologist", a kind-of jobbing scientist-fixer, who can apply tailored solutions with limited resources. The long term, researchlaboratory/institute/university-based work will provide an evolving background of better analysis and understanding of material behaviours and the efficacy of interventions, but is limited in immediate impact, economic relevance and done at a distance from the object of conservation.

This results in what Muñoz Viñas [1] suggests is "endoscience", science for its own sake, which in the opinion of this author is mostly cloaked with the appearance of application, and an appeal to the common good of increased knowledge, even if the results rarely contribute directly to active conservation. In defence of this activity, it is in large part good science, and can be justified in isolation. In this way there is the maintenance of the separation of Muñoz Viñas' conservators and the rest of the conservation stakeholders (Fig 1). Much of what passes for heritage science, published in journal articles falls in this category of endoscience, and applied conservation in the mostly "grey" literature. If progress is to be made on the application of science in heritage, then a change in communication is needed at all stages of the process, where scientific methodological approaches can be valued by conservators, and where scientists value and respect the role of conservators and the other guardians of heritage. In the future, a true interdisciplinarity, in training and outlook, is required, where the scientist and conservator become synonymous.

De Giuchen [62], argues that scientists, in the 80's and early 90 's did not adequately engage in proposing actions and measures for the protection of cultural heritage, more commonly being concerned only and narrowly with the composition of materials. This is a charge that could be aimed at microscopists involved with heritage conservation, after all, they are merely describing composition, and by implication also behaviour in time of materials. A question that is often asked, is, does that in practice result in a proposal for the active amelioration of problems, through actions and interventions based on scientific understanding of compositional factors? Communication of the meaning of microscopy based observations and the conclusions reached from it, beyond mere characterisation, as described above, is an important issue, one that probably does not receive sufficient explanation or demonstrative connection to observed problems. However, microscopy possesses a significant communicative tool- it relies on imagery, which can communicate instantly and often with great clarity, allowing the viewer, even if a non-microscopist, to reach their own conclusion, encouraging some ownership of interpretations and therefore of decisions.

It is often the case (anecdotally in this author's experience), that scientific investigations are welcomed by conservators, and others responsible for the care of heritage. By scientific in these circumstances, we usually mean instrumental, microscopy-based or other forms of compositional characterisation, not in particular the methodological approach (i.e. the Scientific Method). The scientific approach is mostly restricted in conservation to high-status projects, most work is restricted in scope and application, and most significantly by time and budget. Strilc [63] implies that scientific methods applied in conservation are not experimental, that they cannot achieve a statistical significance, as the opportunity for repeat analyses are severely constrained, by the very value that we seek to maintain (i.e. sampling is restricted), and therefore the impact of studies is possibly limited, weakening the value placed on it by other conservation stakeholders. This depends on circumstances, as this consideration does not prevent scientific activity occurring, only limiting its application. The degree of the appearance of science and the connection to real conservation vary depending on the questions being asked, who is asking and what materials are available for analysis. Experimentation, in laboratory-based studies of material behaviour, even if related clearly to understanding decay processes in materials, is a longer term strategy to improve conservation treatments. However this is promoted it is far from practical conservation where science is applied directly to the treatment of a heritage object in short timescales. This literal and temporal separation of activity represents a significant challenge. Microscopists and other scientists who become involved in heritage work need to be aware of this and sensitive to the concerns of others workers in the field.

\section{Conclusion}

Microscopy as applied to historic construction materials is a routine but powerful approach to understanding material compositions and behaviours. It serves a role as a scientific- 
technical characterisation that reinforces and provides evidence for authenticity and integrity in heritage assets. However, in common with all scientific methods and approaches to material understanding used in heritage it needs to be appreciated within the context and constraints of conservation philosophy and practice, where science and scientists are not the main actors, and scientific methods are subservient to values-based concerns [1]. Much conservation science is conducted in laboratories and institutes, away from the 'real' heritage of buildings and sites. Conservation science may need to be recognised as having an applied and theoretical divide, operating on short and long timescales respectively, and operating at appropriate levels of rigour.

Communication between disciplines in conservation and a development of the theory of conservation science, by practicing scientists, not just those with a traditional humanities based connection to conservation, will be increasingly important in bridging the gap between these groups. Training may also need to be aligned so that material and methodological scientific methods of analysis are integrated with conservation approaches. Better and earlier integration of science in conservation planning is needed [54], combined with better information exchange and evaluation of results

In conclusion; to quote McCaig [64], "I don't learn much, I'm a man of no improvements"; there is little of originality here, hence the title, save possibly a small contribution to the philosophical framework that joins heritage conservation and science-based investigations of materials.

\section{References}

[1] S. Muñoz Viñas, Contemporary Theory of Conservation, Routledge, 2011.

[2] R.J. Schaeffer, The Weathering of Natural Building Stones, HM Stationery Office, 1932

[3] M. Esterow, Air Pollution Is Eroding World's Stone Art, New York Times, April 13th, 1964.

[4] H. Plenderleith, The Conservation of Antiquities and Works of Art: Treatment, Repair and Restoration, 1st Edition, Oxford University Press, 1956.

[5] P. Coremans, Scientific Research and the Restoration of Paintings, Bulletin de I'Institut Roayla du Patrimoine Artistique, (1961), 10915 (translation in English in N.S. Price, M. K. Tally, A.M. Vaccaro (Eds.), Historical and Philosophical Issues in the Conservation of Cultural Heritage (Readings in Conservation), Getty Conservation Institute, 1996.

[6] N. Khandekar, Preparation of cross-sections from easel paintings. Studies in Conservation (2003) 48. https://doi.org/10.1179/sic.2003.48.Supplement-1.52

[7] F. Gabrieli, F. Rosi, A. Vichi, L. Cartechini, L. Pensabene Buemi, S.G. Kazarian, C. Miliani, Revealing the Nature and Distribution of Metal Carboxylates in Jackson Pollock's Alchemy (1947) by MicroAttenuated Total Reflection FT-IR Spectroscopic Imaging. Analytical Chemistry (2017) 89 (2): 1283-1289. https://doi.org/10.1021/acs.analchem.6b04065

[8] N. Worley, Henry Clifton Sorby (1826-1908) \& the development of thin section petrography in Sheffield, in: P.S. Quinn (Ed.), Interpreting silent artefacts; Petrographic approaches to Archaeological Ceramics. Archaeopress (2009) 1-9.

[9] S. Fais, F. Cuccuru, P. Ligas, C. Giuseppe, M.G. Bianchi, Integrated ultrasonic, laser scanning and petrographical characterisation of carbonate building materials on an architectural structure of a historic building. Bulletin of Engineering Geology and the
Environment (2017) 76(1): 71.

https://doi.org/10.1007/s10064-015-0815-9

[10] M. Young, Thermal Imaging in the Historic Environment, Historic Environment Scotland, Short Guide, 2015.

[11] D. Paoletti, D. Ambrosinia, S. Sfarraa, F. Bisegnab, Preventive thermographic diagnosis of historical buildings for consolidation. Journal of Cultural Heritage (2013) 14: 116-121. https://doi.org/10.1016/j.culher.2012.05.005

[12] S.A. Orr, H.A. Viles, A.B. Leslie, D. Stelfox, Comparability of nondestructive moisture measurement techniques on masonry during simulated wetting. In: J.J. Hughes, T. Howind (Eds.), Science and Art: A Future for Stone. Proceedings of the 13th International Congress on the Deterioration and Conservation of Stone, University of the West of Scotland, Paisley, 6-10 September 2016, (2016) 1: 431-438.

[13] Z. Xu, L. Wu, Y. Shen, F. Li, Q. Wang, R. Wang, Tridimensional Reconstruction Applied to Cultural Heritage with the Use of Camera-Equipped UAV and Terrestrial Laser Scanner. Remote Sensing (2014) 6(11): 10413-10434. https://doi.org/10.3390/rs61110413

[14] C.L. Reedy, Thin-section petrography in studies of cultural materials. J. American Institute for Conservation (1994) 33: 115129. https://doi.org/10.2307/3179421

[15] J. Elsen, Microscopy of historic mortars - a review. Cement and Concrete Research (2006) 36: 1416-1424 https://doi.org/10.1016/j.cemconres.2005.12.006

[16] J.P. Ingham, Geomaterials under the microscope. CRC Press, Taylor and Francis, 2011.

[17] E.K. Hyslop, L.J. Albornoz-Parra, L.C. Fisher, S.L. Hamilton, Safeguarding Glasgow's stone built heritage skills and materials requirements : facade surveys and building stone analysis. Nottingham, UK, British Geological Survey (CR/06/077N), 2006.

[18] E.K. Hyslop, Assessing Stone Decay and the Future Repair Needs of a Sandstone City: a Survey of the Stone Built Heritage in Glasgow, Scotland, Proc. Of the 11th International congress on deterioration and Conservation of Stone, 15-20 September 2008, Torun, Poland, 2008, 1117-1124.

[19] British Standard BS EN 12407. Natural Stone Test Methods: Petrographic Examination. London: British Standards Institution, 2000.

[20] J.J. Hughes, N. Tennent, The petrography of the Giffnock sandstone from the interior of the Kelvingrove Art Gallery and Museum, Glasgow, Proc. Of the 11th International congress on deterioration and Conservation of Stone, 15-20 September 2008, Torun, Poland, 2008, 651-659.

[21] J.J. Hughes, T. Howind (Eds.), Science and Art: A Future for Stone: Proceedings of the 13th International Congress on the Deterioration and Conservation of Stone, Paisley: University of the West of Scotland, 2016.

[22] J.L. Brown, I.A. Simpson, S.J.L. Morrison, W.P. Adderley, E. Tisdall, O. Vésteinsson, Shieling Areas: Historical Grazing Pressures and Landscape Responses in Northern Iceland. Hum Ecol (2012) 40: 81. https://doi.org/10.1007/s10745-011-9456-1

[23] N. Novaković, M. Franković, V. Matović, K. Šarić, S. Erić, Decay products of the kersantite building stone in the monument of the Small Staircase at the Kalemegdan Park (Belgrade, Serbia). In: J.J. Hughes, T. Howind (Eds.), Science and Art: A Future for Stone. Proceedings of the 13th International Congress on the Deterioration and Conservation of Stone, University of the West of Scotland, Paisley, 6-10 September 2016, (2016) 1: 125-132.

[24] J.J. Hughes, Heritage tea-breaks: petrographic characterisation of old masonry materials from Serbia and Slovenia, 14th Euroseminar on Microscopy Applied to Building Materials, Helsigor, Denmark, 2013.

[25] J. Desarnaud, H. Derluyn, L. Grementieri, L. Molari, S. de Miranda, V. Cnudde, N. Shahidzadeh, Salt Weathering of Sandstone During Drying: Effect of Primary and Secondary Crystallisation. In: J.J. Hughes, T. Howind (Eds.), Science and Art: A Future for Stone. Proceedings of the 13th International Congress on the Deterioration and Conservation of Stone, University of the West of Scotland, Paisley, 6-10 September 2016, (2016) 1: 299-308.

[26] M. Ban, A.J. Baragona, E. Ghaffari, J. Weber A. Rohatsch, Artificial ageing techniques on various lithotypes for testing of stone consolidants. In: J.J. Hughes, T. Howind (Eds.), Science and Art: A Future for Stone. Proceedings of the 13th International Congress on the Deterioration and Conservation of Stone, University of the West of Scotland, Paisley, 6-10 September 2016, (2016) 1: 253260. 
[27] G. Borsoi, B. Lubelli, R. van Hees, R. Veiga, A. Santos Silva, Understanding the transport of nanolime consolidants within Maastricht limestone. Journal of Cultural Heritage (2016) 18: 242249. https://doi.org/10.1016/j.culher.2015.07.014

[28] M. Hajpál, Changes in Sandstones of Historical Monuments Exposed to Fire or High Temperature. Fire Technology (2002) 38(4): 373-382. https://doi.org/10.1023/A:1020174500861

[29] L. Mol, M. Gomez-Heras, C. Brassey, O. Green, T. Blenkinsop, The benefit of a tough skin: bullet holes, weathering and the preservation of heritage. Royal Society Open Science (2017) 4: 160335. https://doi.org/10.1098/rsos.160335

[30] B. Middendorf, J.J. Hughes, K. Callebaut, G. Baronio, I. Papyianni, Investigative methods for the characterisation of historic mortarsPart 1: Mineralogical characteristion, Materials and Structures (2005) 38: 761-769. https://doi.org/10.1007/BF02479289

[31] B. Schouenborg, J.-E. Lindqvist, H. Sandström, M. Sanström, K. Sandin, E. Sidmar, Analysis of Old Lime Plaster and Mortar from Southern Sweden, Swedish National Testing and Research Institute, SP Report 34, 1993.

[32] J.J. Hughes, A.B. Leslie, K. Callebaut, The petrography of lime inclusions in historic lime based mortars. Annales Geologiques des pays Helleniques, Edition Speciale (2001) 39: 359-364.

[33] G. Mertens, J. Elsen, R. Brulet, A. Brutsaert, M. Deckers, Quantitative composition of ancient mortars from the Notre Dame Cathedral in Tournai (Belgium), Materials Characterization (2009) 60: 580-585.

https://doi.org/10.1016/j.matchar.2008.09.004

[34] S. Pavia, S. Caro, An investigation of Roman mortar technology through the petrographic analysis of archaeological material. Construction and Building Materials (2008) 22 (8): 1807-1811. https://doi.org/10.1016/j.conbuildmat.2007.05.003

[35] G. Leone, A. De Vita, A. Magnani, C. Rossi, Thermal and Petrographic Characterization of Herculaneum Wall Plasters. Archaeometry (2017) 59: 747-761. https://doi.org/10.1111/arcm.12275

[36] P.S. Quinn (Ed.), Interpreting silent artefacts; Petrographic approaches to Archaeological Ceramics, Archaeopress, 2009.

[37] J.J. Hughes, A. Klemm, Mortars used in traditional granite structures in Aberdeen, unpublished report for Historic Environment Scotland, 2016.

[38] C. Gosselin, K. Scrivener, S.B. Feldman, W. Schwarz, The Hydrations of Modern Roman Cements Used for Current Architectural Conservation. In: J. Válek, J.J. Hughes, C.J.W.P. Groot (Eds.), Historic Mortars: Characterisation, Assessment and Repair, Springer, 2012, 297-308. https://doi.org/10.1007/978-94-007-4635-0 23

[39] T. Schmid, P. Dariz, Determination and imaging of binder remnants and aggregates in historic cement stone by Raman microscopy. J Raman Spectrosc (2013) 44: 882-891. https://doi.org/10.1002/irs.4296

[40] A. Diekamp, R. Stalder, J. Konzett, P.W. Mirwald, Lime Mortar with Natural Hydraulic Components: Characterisation of Reaction Rims with FTIR Imaging in ATR-Mode. In: J. Válek, J.J. Hughes, C.J.W.P. Groot (Eds.), Historic Mortars: Characterisation, Assessment and Repair, Springer, 2012, 105-113. https://doi.org/10.1007/978-94-007-4635-0 \&

[41] S. Johansson, J.E. Lindqvist, Historic Mortars with Burned Alum Shale as an Artificial Pozzolan. In: J. Válek, J.J. Hughes, C.J.W.P. Groot (Eds.), Historic Mortars: Characterisation, Assessment and Repair, Springer, 2012, 77-88. https://doi.org/10.1007/978-94-007-4635-0 6

[42] J. Weber, K. Bayer, F. Pinter, Nineteenth Century "Novel" Building Materials: Examples of Various Historic Mortars under the Microscope. In: J. Válek, J.J. Hughes, C.J.W.P. Groot (Eds.), Historic Mortars: Characterisation, Assessment and Repair, Springer, 2012, 89-103. https://doi.org/10.1007/978-94-007-4635-0 7

[43] T. Freire, A. Santos Silva, M.R. Veiga, J. de Brito, Characterisation of Decorative Portuguese Gypsum Plasters from the Nineteenth and Twentieth Centuries: The Case of the Bolsa Palace in Oporto. In: J. Válek, J.J. Hughes, C.J.W.P. Groot (Eds.), Historic Mortars: Characterisation, Assessment and Repair, Springer, 2012, 141151. https://doi.org/10.1007/978-94-007-4635-0 11

[44] D. Gulotta, D. Saviello, F. Gherardi, L. Toniolo, M. Anzani, A. Rabbolini, S. Goidanich, Setup of a sustainable indoor cleaning methodology for the sculpted stone surfaces of the Duomo of Milan. Heritage Science (2014) 2:6. https://doi.org/10.1186/2050-7445-2-6
[45] M. Godet, V. Verges-Belmin, C. Andraud, M. Saheb, J. Monnier, E. Leroy, J. Bourgon, Laser Yellowing of Heamatite-Gypsum Mixtures: A multi-scale Characterisation. In: J.J. Hughes, T. Howind (Eds.), Science and Art: A Future for Stone. Proceedings of the 13th International Congress on the Deterioration and Conservation of Stone, University of the West of Scotland, Paisley, 6-10 September 2016, (2016) 1: 785-792.

[46] N.H. Tennent, Conservation Science: A View From Four Perspectives. In: S. Bradley (Ed.) The Interface Betweeen Science and Conservation, British Museum Occasional Paper Number 11, British Museum Press (1997): 15-23.

[47] N. Shahidzadeh, J. Desarnaud, D. Bonn, Direct Measurement of Salt Crystallization Pressure at the Pore Scale. In: J.J. Hughes, T. Howind (Eds.), Science and Art: A Future for Stone. Proceedings of the 13th International Congress on the Deterioration and Conservation of Stone, University of the West of Scotland, Paisley, 6-10 September 2016, (2016) 1: 467-474.

[48] J. Murgatroyd, Ancient mortar production in Ostia, Italy: builders and their choices, PhD Thesis, University of Oxford, 2016.

[49] M.D. Jackson, S. Chae, S. Mulcahy et al., Unlocking the secrets of Al-tobermorite in Roman seawater concrete. American Mineralogist (2013) 98: 1669-1687. https://doi.org/10.2138/am.2013.4484

[50] D. Attanasio, C. Boschi, S. Bracci, E. Cantisani, F. Paolucci, The Greek and Asiatic marbles of the Florentine Niobids. Journal of Archaeological Science (2016) 66: 103-111.

https://doi.org/10.1016/j.jas.2015.12.008

[51] R. Douglas-Jones, J. Hughes, S. Jones, T. Yarrow, Science, value and material decay in the conservation of historic environments. Journal of Cultural Heritage (2016) 21: 823-833.

https://doi.org/10.1016/j.culher.2016.03.007

[52] C.M. Kennedy, The Role of Heritage Science in Conservation Philosophy and Practice. The Historic Environment (2015) 6(3): 214-228. https://doi.org/10.1080/17567505.2015.1099925

[53] C. Gerdwilker, A. Forster, C. Torney, E. Hyslop, The impact of science on conservation practice: sandstone consolidation in Scottish built heritage. In: J.J. Hughes, T. Howind (Eds.), Science and Art: A Future for Stone. Proceedings of the 13th International Congress on the Deterioration and Conservation of Stone, University of the West of Scotland, Paisley, 6-10 September 2016, (2016) 1: 769-776.

[54] P.A.T.I. Burman, "Hallowed Antiquity": Ethical Considerations in the Selection of Conservation Treatments. In: N.S. Baer, R. Snethlage (Eds.), Saving our Architectural Heritage: The Conservation of Historic Stone Structures, Dahlem Workshop Report, John Wiley and Sons, 1996, 269-290.

[55] A. Riegl, The modern cult of monuments: its essence and its development, 1903. Translation in English: N.S. Price, M.K. Tally, A.M. Vaccaro (Eds.), Historical and Philosophical Issues in the Conservation of Cultural Heritage (Readings in Conservation), Getty Conservation Institute, 1996, 69-83.

[56] International Council on Monuments and Sites ICOMOS, The Nara Document on Authenticity, 1994.

[57] International Council on Monuments and Sites ICOMOS, The Athens Charter for the Restoration of Historic Monuments, 1931.

[58] International Council on Monuments and Sites ICOMOS, International Charter for the Conservation and Restoration of Monuments and Sites, The Venice Charter, 1964.

[59] H. Plenderleith, Introductory Lecture, Session Second B, "The monument for the man", Records of the 2nd International Congress of Restoration, ICOMOS, Venezia, 25-31 May 1964

[60] F. Francioni, F. Lenzerini, The Destruction of the Buddhas of Bamiyan and International Law. European Journal of International Law (2003) 14(4): 619-651. https://doi.org/10.1093/ejil/14.4.619

[61] G. Torraca, The Scientist's Role in Historic Preservation with Particular Reference to Stone Conservation. In: National Research Council, Conservation of Historic Stone Buildings and Monuments, National Academy Press, Washington DC, 1982, 13-18.

[62] G. de Guishen, Scientists and the preservation of cultural heritage. In: N.S. Baer, C. Sabbioni, A.I. Sors (Eds.), Science, Technology and European Cultural Heritage. Proceedings of the European Symposium, Bolonga, Italy 13-16 June 1991, ButterworthHeinemann, 1991, 17-26. https://doi.org/10.1016/B978-0-7506-0237-2.50010-1

[63] M. Strlic, A Brief Theory of Heritage Science, London: National Heritage Science Forum, 2015

[64] N. MacCaig, Ineducable me (poem first published in 1977). In: The Many Days: Selected Poems of Norman MacCaig, Polygon, 2010. 